\title{
Dual-Use and Infectious Disease Research
}

\author{
Nicholas G. Evans
}

\begin{abstract}
Despite rapid advance in the prevention, diagnosis, and treatment, infectious diseases remain a central challenge for global health policy. In the twenty-first century, the life sciences_-including microbiology, virology, and immunologyhave been marshalled as key tools in the fight against infectious disease, and the promotion of global health. Rapid advance in these fields, however, has given rise to the "dual-use dilemma," when one and the same piece of scientific research or technology has the capacity to help or harm humanity. While not unique to fields that address infectious disease, contemporary cases of dual-use research are largely identified in the context of the life sciences. In this chapter I outline the debate about dual-use research in the life sciences, in particular the ethics of dual-use research. After a historical overview of the dual-use dilemma in the twenty-first century, I examine ethical issues in attempting to trade off the risks and benefits of dual-use research. I address how we select alternative, less risky experiments; translational issues arising for dual-use research; and political commitments to realise the benefits and mitigate the risks arising from such research. I then discuss the governance of dual-use research, before concluding with a brief discussion on priority setting in infectious disease research as a path forward for policymakers.
\end{abstract}

Keywords Scientific research $\cdot$ Dual-use $\cdot$ Gain of function $\cdot$ GOF

\section{Introduction: Two Stories of Emerging Infectious Diseases}

Infectious diseases present an important challenge for the health and security of modern communities. Despite staggering advances in medicine and public health through the twentieth century, common infectious diseases remain one of the top

\footnotetext{
${ }^{1}$ GBD 2016 Causes of Death Collaborators (2017).
}

N. G. Evans (ه)

Department of Philosophy, University of Massachusetts Lowell, Lowell, MA, USA

e-mail: Nicholas_evans@uml.edu 
five causes of years of life lost around the globe. ${ }^{1}$ An important component of the continued fight against infectious diseases is recognised to be basic scientific research into the biology of infectious organisms: microbiology, virology, and immunology among others.

In the beginning of the twenty-first century, two significant events mobilised global attention on infectious diseases as both a health and security challenge. The first occurred in 2001, when letters containing bacillus anthracis were sent through the United States Postal Service, ultimately killing five people of twenty-two who were infected. ${ }^{2}$ The so-called "amerithrax" attacks were decisive in pushing the threat of infectious into the national security spotlight.

In response to the amerithrax attacks, the United States Congress passed the Project Bioshield Act in 2004. Among other things, the act authorised the Secretary of Health and Human Services to conduct and support research and development activities for countermeasures in biological emergencies, and increased the capacity of the National Institutes of Health and National Institute of Allergy and Infectious Diseases to conduct research and respond to biological threats. In 2006, the Pandemic and All-Hazards Preparedness Act established the Biomedical Advanced Research and Development Authority, which would manage Project BioShield and guide research and development in aid of creating novel medical countermeasures against infectious diseases and Chemical, Biological Radiological, and Nuclear weapons.

In 2003, the emergence of severe acute respiratory syndrome (SARS) shocked the international community. While the threat of "emerging infectious diseases" (EID) had been flagged by the US and Canada in the 1990s, ${ }^{3}$ SARS was frightening both for the pace at which it moved, and the unexpected nature of its emergence. After more than 8000 cases over 17 countries, and killing almost $10 \%$ of those infected, SARS was described as a "wake-up call" by then Director-General of the World Health Organisation (WHO) Margaret Chan. In 2005, in part as a response to SARS, the International health Regulations (IHR) entered into force. The IHR, among other things, coordinates the reporting of events to the WHO that may represent a "Public Health Emergency of International Concern," such as a major influenza pandemic. It also requires Parties to the IHR - the 196 members of the World Health Assemblyto ensure their national health surveillance and response capacities meet criteria set out in the Regulations.

These initiatives have thrown basic scientific research into the spotlight as a key weapon against the fight against infectious disease. As human and non-human animal communities become more interconnected, our climate changes, we encroach evermore into our remaining wilderness, and use existing drugs to fight diseases, our disease landscape is changing. As our mastery of biology changes, moreover, it becomes increasingly plausible that a malevolent actor, non-state group, or nation could create and deploy biological weapons. These dual biological threats-so-called naturally occurring and human-created-have situated modern biology as both a threat to human health and security, and its ultimate saviour.

\footnotetext{
${ }^{2}$ Inglesby et al. (2002).

${ }^{3}$ Weir (2012).
} 
The name we give to this problem is the dual-use dilemma: when one and the same piece of scientific research or technology has the capacity to help or harm humanity. While much if not most scientific research is dual-use in some trivial sense, i.e. it has the capacity to inflict some harms and/or some benefits, the kind of dual-use research I am concerned with is research that has the capacity to inflict very great harms and/or benefits. Such a benefits might include, for example, the cure for a highly virulent infectious disease or "potential pandemic pathogen," such as avian influenza. A commensurate potential harm might be the creation of such a potential pandemic pathogen. ${ }^{4}$ This research poses an ethical issue because the capacity of dual-use research to be used or misused invokes questions, inter alia, about the limits of scientific freedom, and kinds of values science promotes, or ought to promote, and the distribution of the risks and benefits of scientific innovation in society. Dual-use presents a dilemma because, in some cases, it is not clear where the balance of risks and benefits, or rights, lies.

In what follows, I outline the debate about dual-use research in the life sciences, beginning at the turn of the twenty-first century. I then examine ethical issues arising in the analysis of the balance of risks and benefits of dual-use research. I drill further into an inquiry into risks and benefits and examine how we select alternative experiments, translational issues arising for dual-use research, and political commitments to realise the benefits and mitigate the risks of dual-use research. I then turn to governance issues, and those of scientific freedom. I conclude with a brief discussion of priority setting, and how the foundational policies that promoted basic research in the life sciences may also compromise global health and security.

\section{Dual-Use Research in the Life Sciences}

The story of dual-use is now seventeen years in the making. For ease of reading, I will describe three broad phases of the debate: the early years (2001-2011); the "ferret flu" years (2011-2014); and the gain-of-function (GOF) debate (2014-present). Each phase is fascinating and worthy of a separate inquiry, but I restrict myself to the central points of each episode that are needed for the analysis to come.

\subsection{The Early Years: Mousepox, Polio, and Toxic Milk}

While the story of dual-use has, inevitably, come to revolve around the United States and its policies, the dual-use dilemma in the life sciences has its origins in Australia. Ronald Jackson and Ian Ramshaw worked as part of a team sponsored by the Australian Commonwealth Scientific and Industrial Research Organisation (CSIRO) and the Australian National University (ANU) to create a recombinant form of the

${ }^{4}$ Evans et al. (2015a). 
myxoma virus, a poxvirus that infects rabbits. In the 1950s, myxoma had been used to control the plagues of rabbits that had devastated the Australian countryside since the late nineteenth century. While the initial release was almost totally successful, the small number of rabbits that survived inevitably did what they did best-bred like rabbits-back to their original population size. ${ }^{5}$ Ramshaw, a student of Frank Fenner (better known for his work eradicating smallpox and a stunt in which he and two colleagues inoculated themselves with the myxoma virus, to demonstrate its safety in humans ${ }^{6}$ ), was along with Jackson charged with coming up for a cure to this resistance, and put an end to the plague.

The strategy Jackson and Ramshaw used was simple: use the viral machinery of myxoma to render rabbits infertile. In order to make their lives easier in the early stages of research - again, basic scientific research - they chose to use mice and the ectromelia or mousepox virus as their model organism. Rabbits are more expensive and larger than mice, making experiments with them less convenient to use; ectromelia is also a better-characterised poxvirus than myxoma. Their experiments with ectromelia showed some initial success: mice infected with the virus would remain infertile for between five and nine months. ${ }^{7}$

Jackson and Ramshaw wanted higher rates and durations of infertility, so they sought to further enhance the virus to express the interleukin-4 protein, a cytokine present in mammals that plays a key role in the immune system. By encouraging the production of interleukin-4, the hope was that the mouse's immune system would actually assist the virus in the attack against its host's reproductive system. The results, however, were unexpected. A paper in 2001 by the team in the Journal of Virology reported that more than sterilizing the mice, the virus outright killed its hosts. And not just sometimes: the virus killed $100 \%$ of the normal mice and vaccinated mice, and $60 \%$ of mice already genetically resistant to ectromelia. ${ }^{8}$

The central issue that arose from this research is that while mousepox doesn't infect humans, smallpox does. A disease that killed more humans than any other in history, smallpox was declared eradicated on May 8 of 1980 by Fenner, and humanity's victory over the virus is arguably one of the greatest triumphs in the history of modern medicine and public health. Few people today have been vaccinated against smallpox-why vaccinate against an extinct species?-and those who have lost their immunity long ago. Until 2014, when six vials of smallpox were discovered in a freezer in the old National Institutes of Health campus in Bethesda, MD [SZABO], it was thought that the virus only survived under lock and key at the Centers for Disease Control (CDC) in Atlanta, GA, and VECTOR, the Russian equivalent of the CDC in Sverdlosk.

The publication of the results of Jackson and Ramshaw's work coincided with the Amerithrax attacks, and in early 2002 the US Central Intelligence Agency released a report titled The Darker Bioweapons Future, listing the mousepox study as evidence

\footnotetext{
${ }^{5}$ Bartrip (2008).

${ }^{6}$ Henderson (2011).

${ }^{7}$ Jackson et al. (1998).

${ }^{8}$ Jackson et al. (2001).
} 
that the capacity for state and non-state actors to build novel, sophisticated biological weapons already existed. ${ }^{9}$ In response, the US Government commissioned a committee of the National Research Council to assess the risk of dual-use research in the life sciences. That committee's report, Biotechnology Research in an Age of Terrorism, later named the "Fink report" after the committee's chair Gerald Fink, recommended among other things the education of scientists on dual-use research, the establishment of the National Science Advisory Board for Biosecurity (NSABB), and the international harmonisation of biosecurity norms. ${ }^{10}$ It also outlined seven "experiments of concern", which:

1. Would demonstrate how to render a vaccine ineffective;

2. Would confer resistance to therapeutically useful antibiotics or antiviral agents;

3. Would enhance the virulence of a pathogen or render a nonpathogen virulent;

4. Would increase transmissibility of a pathogen;

5. Would alter the host range of a pathogen;

6. Would enable the evasion of diagnostic/detection modalities;

7. Would enable the weaponisation of a biological agent or toxin;

A follow up report in 2006, Globalisation, Biosecurity, and the Future of the Life Sciences, (the "Lemon-Relman report") further recommended increased capacity for public health to respond to biological weapons, the promotion of a "culture of awareness" in the scientific community, increased biological expertise in the security community, and a broader assessment of what constituted a "threat" in dual-use than its predecessor. In the same year the NSABB was founded within the National Institutes of Health (NIH) as an advisory committee to the NIH and US Government on issues related to dual-use.

In the meantime, dual-use research continued to crop up. In 2002, scientists at State University of New York Stony Brook, funded by the US Defense Advanced Research Projects Agency (DARPA), successfully synthesised the poliovirus from its base sequence. ${ }^{11}$ This marked the first time a virus had been synthesised, and was by all measure a scientific breakthrough. Yet while the polio had attenuated virulence due to difficulties in the synthesis process, ${ }^{12}$ it opened the way to the synthesis of more complex and dangerous agents for use as biological weapons_-again, such as smallpox.

In 2005, two researchers from Stanford modelled an attack on the US food supply, using the example of the release of the botulinum toxin in the milk supply. ${ }^{13}$ Botulinum toxin is the most powerful toxin on earth, and widely used in clinical medicine for its paralytic properties. It, however, is a potent biochemical toxin, has been used in former biological weapons programmes (including the former Soviet

\footnotetext{
${ }^{9}$ Central Intelligence Agency (2003).

${ }^{10}$ National Research Council (2004a).

${ }^{11}$ Cello et al. (2002).

${ }^{12}$ Selgelid and Weir (2010).

${ }^{13}$ Wein and Liu (2005).
} 
bioweapons program, which ran unknown to the world until 1992). ${ }^{14}$ Moreover, it can be obtained, in bulk, online as part of discount or counterfeit cosmetic surgery products (where the toxin goes by the trade name Botox). ${ }^{15}$ The research predicted that up to 200,000 people, mainly children and the elderly, would die if $1 \mathrm{~kg}$ of the toxin was released at the right point in the milk distribution system in the US. While a clear warning for government, it also was charged with providing a blueprint for terrorists, which led the US government into an unsuccessful plea to have the publication suppressed. ${ }^{16}$

At the same time, scientists at the CDC proceeded to piece together the genetic sequence for the 1918 H1N1 "Spanish Influenza" that killed 50-100 million people. ${ }^{17}$ The scientists later synthesised the virus, and tested its virulence in nonhuman primates. ${ }^{18}$ The NSABB was consulted on the dual-use aspects of the research: while on the one hand scientists argued that the reconstruction of the virus could give insight into what made it so devastating, ${ }^{19}$ concerns remained that the creation of such a virus posed a risk if aspiring bioweaponeers were to do the same. ${ }^{20}$

In 2007, the NSABB released a draft framework for the oversight of dual-use life sciences research. In this, they codified the term "dual-use research of concern" (DURC), initially proposed by the Fink report but now defined as

[r]esearch that, based on current understanding, can be reasonably anticipated to provide knowledge, products, or technologies that could be directly misapplied by others to pose a threat to public health and safety, agricultural crops and other plants, animals, the environment, or materiel. ${ }^{21}$

This framework maintained that, while regulation on the funding, conduct, or communication of dual-use research might be necessary, the judgement of researchers was still the dominant factor in preventing the misuse of emerging life sciences research and technology. ${ }^{22}$ The framework recommended further awareness raising, education, and training in the responsible communication of research, defining a period of dual-use that centred on the self-governance of individual scientists.

\subsection{Ferret Flu}

The debate about dual-use calmed in the wake of the 1918 flu experiments. In 2011, this calm was disrupted with the announcement that two papers, slated for publication in Science and Nature, had described the creation of recombinant strains of highly

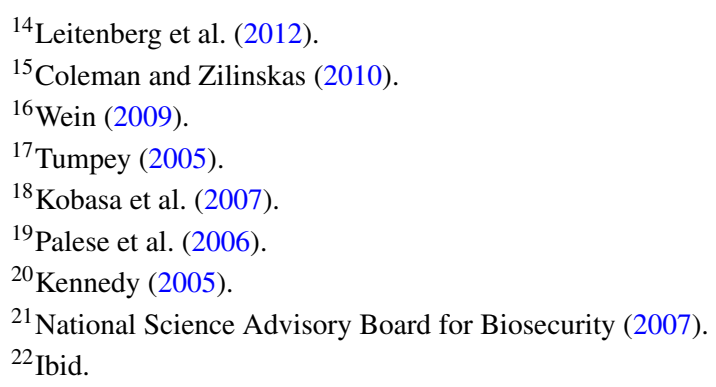


pathogenic avian influenza (HPAI) H5N1 that were transmissible via respiratory droplets (were "airborne") between ferrets. ${ }^{23}$ The studies were significant because HPAI H5N1, up until 2016, only produced 854 recorded cases of H5N1 in humans, but $52 \%$ of those infected had died. In comparison, the 1918 flu pandemic had a case fatality rate of approximately $2.5 \% .{ }^{24} \mathrm{HPAI} \mathrm{H} 5 \mathrm{~N} 1$ only infected humans from birds, primarily poultry stocks, but had not undergone sustained transmission between humans in the wild. Ferrets are a common immunological model for flu pathogenesis and transmission in humans; the implications of the studies were that wild-type HPAI H5N1 could, in principle, develop the capacity to transmit between humans and thus trigger a potential pandemic with unprecedented lethality.

These "gain of function" (GOF) studies, so called because they followed a common virology practice of inducing novel mutations into viruses to modify their function, were conducted independently by groups at the University of WisconsinMadison in the US, and Erasmus University in the Netherlands. The NSABB was asked to review the studies, and recommended that both studies be redacted, suppressing the sequence information and key methods of the studies that would give individuals the capacity to reproduce the viruses. ${ }^{25}$ Their reasoning followed the model for dual-use: while proponents of the work claimed that the research would improve surveillance efforts by identifying the mutations to look for that would signal an impending pandemic, and enhance efforts to create medical countermeasures against pandemic HPAI, critics noted that the same research offered a method to develop precisely such a virus for use on the human population. ${ }^{26}$

In 2012 the authors of the 2011 H5N1 studies and a group of colleagues declared a moratorium on GOFR on highly pathogenic $\mathrm{H} 5 \mathrm{~N} 1$ avian influenza strains in a letter to Science. They wrote the moratoria should last for 60 days, and include a meeting of experts to discuss how best to assure the public, provide room for discussion of the merits and risks of the studies, and find solutions to challenges posed by the research. ${ }^{27}$ The moratorium ultimately lasted 9 months, after the US Government requested an indefinite extension on the moratorium to allow time to craft appropriate policy. ${ }^{28}$ During this time, the World Health Organisation (WHO) held a meeting of experts in the manner suggested by the authors of the moratorium letter, which concluded with a rough scientific consensus that both studies should ultimately be published in full. ${ }^{29}$ The NSABB subsequently reviewed and approved revised versions of the two papers, which included additional discussion of the public health benefits the authors believed could result from the work. ${ }^{30}$

\footnotetext{
${ }^{23}$ Enserink (2011).

${ }^{24}$ Taubenberger and Morens (2006).

${ }^{25}$ National Science Advisory Board for Biosecurity (2011).

${ }^{26}$ Evans (2013).

${ }^{27}$ Fouchier et al. (2012), Herfst (2012).

${ }^{28}$ Casadevall and Shenk (2012).

${ }^{29}$ Fouchier et al. (2012).

${ }^{30}$ National Science Advisory Board for Biosecurity (2012).
} 
The papers were published in $2012,{ }^{31}$ and in January 2013 scientists declared the moratorium over, claiming "the aims of the voluntary moratorium have been met in some countries and are close to being met in others." ${ }^{32}$ In February 2013, the Department of Health and Human Services published policy describing seven criteria that studies like the H5N1 studies would have to meet in order to be funded. These criteria included high significance for public health, the lack of feasible alternatives to answer the same scientific question, and the appropriate management of bio safety and Biosecurity risks. ${ }^{33}$

\subsection{Biosafety and Gain of Function}

From their final recommendations in 2012, the NSABB did not meet again until $2014 .{ }^{34}$ That year, two sets of revelations reignited the GOF debate with a slight twist. First, it was revealed that gain of function studies involving the creation of novel, recombinant "potential pandemic pathogens" (PPPs) such as those in 2011 were being funded by the US, China, ${ }^{35}$ the European Union, ${ }^{36}$ private and public funders in the UK, ${ }^{37}$ and the governments of Japan, ${ }^{38}$ and the Netherlands. ${ }^{39}$ The viruses had diversified, as well: in 2014, GOF had proliferated beyond HPAI H5N1 to $\mathrm{H} 7 \mathrm{~N} 1,{ }^{40} \mathrm{H} 9 \mathrm{~N} 1,{ }^{41}$ and $\mathrm{H} 7 \mathrm{~N} 9 .{ }^{42}$

Second, the debate about dual-use shifted from predominantly biosecurity concerns to those biosafety concerns, motivated by a number of problematic incidents involving US laboratories. First, the CDC announced that an accidental release of anthrax had occurred when an improperly inactivated sample had been moved out of a high containment laboratory, potentially exposing 70 employees to the bacterium. ${ }^{43}$ Next, the United States Department of Agriculture (USDA) reported that a shipment of low pathogenicity avian influenza from the CDC had been contaminated with HPAI; the researchers at USDA discovered this when poultry inoculated with the samples began dying at an alarming rate. ${ }^{44}$ Finally, a former Food and Drug

\footnotetext{
${ }^{31}$ Herfst et al. (2012), Imai et al. (2012).

${ }^{32}$ Fouchier et al. (2013).

${ }^{33}$ The United States Government (2013).

${ }^{34}$ Michael Osterholm and Paul Keim, personal communications, 2014.

${ }^{35}$ Zhang et al. (2013).

${ }^{36}$ Herfst and others (n 30).

${ }^{37}$ Shelton et al. (2013), Watanabe et al. (2014).

${ }^{38}$ Ibid.

${ }^{39}$ Herfst and others (n 30).

${ }^{40}$ Sutton et al. (2014).

${ }^{41}$ Kimble et al. (2014).

${ }^{42}$ Richard et al. (2013).

${ }^{43}$ Centers for Disease Control and Prevention (2014a).

${ }^{44}$ Centers for Disease Control and Prevention (2014b).
} 
Administration (FDA) lab on the National institutes of Health Campus in Bethesda, Maryland, reported finding a shoe box full of dangerous viral samples, including a number of samples of smallpox. ${ }^{45}$

In response to these events, and the prompting of concerned scholars and scientists, ${ }^{46}$ the US Government imposed a funding pause on 18 government funded GOF experiments on influenza, severe acute respiratory syndrome (SARS) coronavirus, and Middle East respiratory syndrome (MERS) coronavirus; paused the future funding of such research; and advised private funders to do the same. This pause came with the a "deliberative process" involving the National Academies of Science, ${ }^{47}$ $\mathrm{NSABB}$, a risk and benefit assessment of $\mathrm{GOF}^{48}$ and an ethics white paper on GOF research. $^{49}$

The result of this process was a series of recommendations produced by the NSABB on the funding and conduct of GOF research. The NSABB acknowledged there was some GOF research that ought not to be conducted for security and safety reasons. ${ }^{50}$ They provided a series of policy guidelines that would be reproduced, with minor amendments, in the White House Office of Science and Technology Policy's Recommended Policy Guidance for Departmental Development of Review Mechanisms for Potential Pandemic Pathogen Care and Oversight (P3CO). ${ }^{51}$ This guidance outlined the policy principles that should guide the funding and conduct of GOF research moving forward, and noted that an agency's adoption of policy consistent with $\mathrm{P} 3 \mathrm{CO}$ would constitute the end of the funding pause. In December of 2017, the US Department of Health and Human Services released such a policy, ${ }^{52}$ and the pause was deemed to be at an end.

This is only a sketch of the debate on dual-use research, a debate that has taken seventeen years and is still ongoing. For example, researchers in Canada in 2016 announced that they had successfully synthesised the horsepox virus, an extinct poxvirus that shares homology (genetic structure) with smallpox. This has scared some policymakers, but I set it aside here because while interesting, it shares enough features with the polio case and the 1918 flu case that it doesn't raise novel ethical issues. Rather, I use the above as context for detailing key ethical issues that will make up the rest of this chapter.

\footnotetext{
${ }^{45}$ Dennis and Sun (2014).

${ }^{46}$ For example, the Cambridge Working Group Consensus Statement on the Creation of Potential Pandemic Pathogens (PPPS), of which the author is a founding member and author. http://www. cambridgeworkinggroup.org.

${ }^{47}$ National Academies of Sciences, Engineering and Medicine (2016), National Research Council Institute of Medicine (2015).

${ }^{48}$ Gryphon Scientific (2016).

${ }^{49}$ Selgelid (2016).

${ }^{50}$ National Science Advisory Board for Biosecurity (2016).

${ }^{51}$ Office of Science and Technology Policy (2017).

${ }^{52}$ Department of Health and Human Services (2017).
} 


\section{Risks and Benefits}

Dual-use has, historically, been framed as a question of the balance of risks and benefits posed that inhere to scientific research. The literature on GOF research, in particular, focused on the question of whether the risks of GOF research, i.e. the accidental or deliberate release of a novel PPP causing a global pandemic, were outweighed by the potential benefits of the research in terms of contributions to science, disease surveillance, and medical countermeasures. ${ }^{53}$ A preliminary question is, then, whether this is all that really matters for the purpose of dual-use.

To illustrate the pervasiveness of this framing, consider that the Fink report. When discussing the balance between scientific freedom and security, the committee focussed in the main on scientific freedom as instrumentally valuable to achieving scientific and material progress. ${ }^{54}$ The Lemon-Relman report concurred, citing National Security Decision Directive 189 (NSDD-189) as the basis for maintaining policies and practices that promoted the free and open exchange of information in the life sciences. NSDD-189 is significant in US science policy: it makes a canonical distinction between "basic" and "applied" scientific research, and affirms the US national interest in the open communication of basic scientific research (i.e. free of government classification). The basis for this, in turn, is the strategic interest the US has in using basic science research to achieve its economic and security goals. ${ }^{55}$

But scientific freedom is more than an instrumental good. On the one hand, scientific freedom is important for its own sake-we might think that, all other things being equal, a scientific enterprise in which individual scientists make their own choices about which research to pursue (conduct, communicate, etc.) is better than one in which scientists are restrained in their activities. ${ }^{56}$ Moreover, scientific research might be considered to be derivative of other important civil liberties, such as freedom of speech and/or inquiry. ${ }^{57}$

Any governance measure that purports to keep scientific research open in order to maximise the benefits of scientific research must also contend with a lack of necessary or sufficient connection between scientific freedom and scientific results. The physical sciences, in particular, have a strong tradition of achieving incredible progress in highly restrictive environments. The maintenance of "classified communities" in which scientists are free to communicate, but only within a small community, has created rapid scientific progress (though perhaps not always promoting the values we want). ${ }^{58}$ While the life sciences does not currently adopt such a practice-or, at least, not widely - there is no in principle reason why scientific freedom is a necessary condition of scientific advancement.

\footnotetext{
${ }^{53}$ Casadevall and Imperiale (2014), Evans et al. (2015b).

${ }^{54}$ National Research Council (n 8).

${ }^{55}$ Hindin et al. (2017).

${ }^{56}$ Evans (n 24).

${ }^{57}$ Miller and Selgelid (2008).

${ }^{58}$ Evans (2000), Westwick (2000).
} 
This case is illustrative of how the debate about dual-use frequently elides conceptual nuances about the ethics of pursuing research that poses serious, at times population-level risks and benefits to the public. In some cases, this may not make a difference to ultimate decisions. One could imagine, for example, an experiment outlining a recombinant strain of smallpox modified in the style of the mousepox experiment, and confirmation that this strain had the same transmissibility as wildtype smallpox, but with $100 \%$ lethality and the ability to overcome antivirals (which the Australian mousepox strain did). ${ }^{59}$ We might think that in such an extreme case, whether or not there is some additional value to scientific freedom is a moot point.

In many if not most other cases, however, the risks are less than existential, ${ }^{60}$ and the potential benefits less than beatific. These make up the paradigm cases of dualuse, though they may not in the future. In those cases, we need to account for other considerations. A preliminary issue is that the way we account for risks and benefits may differ. This was an acute challenge for the GOF risk and benefit assessment. While risk could be modelled numerically, the analysis of benefits was constrained to a qualitative examination of potential benefits, based in the main on open-ended interviews with subject matter experts in health, science, and security. ${ }^{61}$

This empirical issue points to a series of broader conceptual issue for dual-use research. We typically and perhaps justifiably tend to think of risks and benefits as straightforwardly comparable or commensurate. But this need not be the case. To begin, it isn't clear that the kinds of benefits we typically describe for dual-use infectious disease research — saving lives — are morally equivalent to the typical risks we assign to dual-use research in terms of lives lost. We could imagine a dual-use dilemma, for example, in which there was the expectation of some positive use saving 1000 lives, and the risks of misuse resulting in an expected 1000 lives taken by a malevolent user. It isn't clear that saving 1000 lives from an avoidable death that is not murder are morally equivalent to 1000 lives taken by a malevolent actor. Some might claim "justice delayed is justice denied" in the case of scientific progress; those same people may be reluctant to say that their failure to pursue one line of research is effectively the killing of those people.

This dovetails into a stronger issue around the pursuit of alternatives of dual-use research. Advocates for GOF research have argued that GOF as a methodology has unique epistemic merits. While other experiments may allow us to demonstrate the potential for a pathogen to alter its host range or experience enhanced transmissibility or virulence, advocates maintain that only GOF can show us this is possible. As such, a change to an alternate methodology deprives us of the one methodological tool we have to conclusively prove that a (wild-type) virus can acquire the potential to cause a human pandemic. ${ }^{62}$

\footnotetext{
${ }^{59}$ Robbins et al. (2005), Connell (2012).

${ }^{60}$ This is not to say that existential risks do not deserve nuanced analysis, just that in some cases the risks may outweigh all other benefits a fortiori. See e.g. Bostrom (2014).

${ }^{61}$ Gryphon Scientific (n 45).

${ }^{62}$ Casadevall et al. (2014).
} 
Yet it isn't clear either that this is truly unique of GOF research, or that this unique benefit is the benefit that matters for an analysis of dual-use research. One alternate experiment that might be to choose specific parts of a viruses to investigate: to determine whether a virus with a substituted HA protein would bind to human receptors we could use an attenuated virus rather than its wild-type progenitor, rendering our experiment much safer. A more radical alternative might be cell-free study of single proteins - for example, $\mathrm{H} 5$ or $\mathrm{H} 7$ receptor binding to mammalian sialic acids - and eliminate the need for a live virus (at least, in initial research). ${ }^{63}$

These alternate experiments offer to potentially answer the same question. Yet why consider only these? We could offer a series of alternatives that accomplish the same benefit qua preventing the spread of some infectious disease through alternate means, even those that do not rely on further infectious disease research. We know, for example, that global health capacities are still sorely lacking in many nations, including the developed world. We could envisage abandoning potential dual-use research for a public health solution; simply allocating the funds we otherwise would have spent on that research to, say, public health surveillance. We could, alternatively, spend the same money in some totally other way to benefit human health-improving traffic safety, for example. ${ }^{64}$

This is still fairly simple; for other instances of dual-use, it is even less clear. In the case of the mousepox study, the claimed potential benefit was the eradication of rabbit plagues. As an Australian, I can confidently say that this would lead to improved wellbeing for humans in Australia, but there are also a range of important values that might be at stake: the value of the natural environment for its own sake; of biodiversity; of the well-being of intelligent non-human mammals (of which there are many) in the country; redressing environmental injustices imposed upon the indigenous human population of Australia, of whom those who live on their traditional lands are worst affected by the undermining of the Australian natural environment.

In principle, the kinds of harms about which we should be concerned are similarly subject to variation. What is commonly unacknowledged about the mousepox case is that even before the IL-4 mutation that made it so deadly, what is unrecognised about the research programme is that it was one in which scientists were on a quest for an infectious contraceptive. Conceivably, this could be used by some kind of malevolent actor to render humans infertile, which would undermine a serious, central life plan of many billions of people. ${ }^{65}$ While there is some welfare component to this kind of harm, we might think that people's autonomy is undermined, as is their ability to flourish, in a way that is (dis)valuable for its own sake. ${ }^{66}$

Talk of flourishing identifies ways in which we might think about different timescales for risks. The central debate around dual-use revolves around the prospect of acute and extreme harms. The paper focusing on botulinum toxin in the US milk supply, for example, claimed that the use of $1 \mathrm{~kg}$ of botulinum toxin could cause

\footnotetext{
${ }^{63}$ Evans (2018).

${ }^{64}$ Evans (n 24).

${ }^{65}$ Pennings (2008).

${ }^{66}$ Kleinig and Evans (2013).
} 
an expected 200,000 deaths. This is a large, single-source attack, comparable to a disease pandemic - between four and eight years of flu mortality in the US, rolled into a single attack. While these attacks undoubtedly arise from collective actions, ${ }^{67}$ they culminate in an event that we can (and maybe should) treat in the singular.

In contrast, consider deaths from road fatalities, or something similar. Approximately 32,000 people die on American roads each year. They do so, however, a few (or one) at a time. Is such a thing possible in the context of dual-use, and should it feature in a scheme to weigh the risks and benefits of such research? To the former, the answer is a likely "yes." Consider, for example, that in the last year there have been three very public self-experiments in synthetic biology, a discipline that seeks to transform biology into a predictable and tractable engineering discipline, and which has been identified as a field with strong dual-use potential. ${ }^{68}$ All three cases-two in which individuals injected themselves with CRISPR-Cas9 constructs, ${ }^{69}$ another in which an individual with human immunodeficiency virus (HIV) discontinued his antiretroviral treatments and injected himself with an experimental gene therapy ${ }^{70}$ were done outside of laboratory conditions, without safety equipment. Or consider that in the last half decade there have been a slew of attempted ricin poisonings committed by individuals who distilled the compound in their homes. ${ }^{71}$ While the last example is in chemistry and not biology, it seems clear that there are in principle malevolent, reckless, or otherwise problematic cases where biology is misused, but on a small scale. We should then be concerned that, as biology diffuses from the province of a few to totally ubiquitous, that even a low rate of individual or small group-harming misuses could lead to a large number of deaths.

Responses to these events might have different implications. On the one hand, it is possible that a large-scale biological attack will happen in the next decade: security experts to whom I have spoken often go further to say such an attack is likely. ${ }^{72}$ But in the meantime, an unregulated market for biologics on the Internet, pursued by amateur biologists, could spark a rash of deaths that exceeds a large biological attack over the medium term to misadventure, lax biosafety, and the proliferation of biological technologies. ${ }^{73}$

On the other hand, companies and groups often have strong incentives to avoid predictable, statistically likely deaths. There are a serious of reputational and resource

\footnotetext{
${ }^{67}$ Evans (2015).

${ }^{68}$ Tucker (2011).

${ }^{69}$ Zhang (2018).

${ }^{70}$ Brown (2017).

${ }^{71}$ Evans (2015). A law enforcement agent, speaking on conditions of anonymity, has noted that the number of these cases is an order of magnitude larger than reaches news outlets; most of these attempts, however, are not as advanced as those attempts that do make headlines.

${ }^{72}$ These claims have been made at meetings subject to, or by speakers who invoked The Chatham House Rule: The first meeting of the 2015 class of the Emerging Leaders in Biosecurity Initiative Fellowship in Washington, DC., March 2015; The Australian National University meeting on dualuse research in 2008 funded under the auspices of the Wellcome Trust Grant "Building a Sustainable Capacity in Dual-Use Bioethics;" among others.

${ }^{73}$ Evans and Selgelid (2014).
} 
incentives, for example, that might make a biotechnology startup likely to seek to avoid deaths caused by users buying inadequately quality-controlled products. On the other hand, the likelihood of a mass-casualty event being caused by that same firm, or the kind of cost it would incur on a limited-liability actor (who lacks the resources or is protected from full liability) might attenuate incentives to act. A world of private biological enterprise might under protect us from very large, very rare harms. ${ }^{74}$

\section{Translation}

The above discussion has focussed in the main on risks; a look at the literature will find this to be relatively normal for the dual-use dilemma. Benefits tend to receive much less explicit critical analysis, although all of the challenges described above arguably can all be said to occur if one were to look at the benefits side of the dilemma. Are there any issues that apply, however, uniquely, distinctly or first and foremost to benefits?

I would argue that a critical issue facing benefits is that of translation. The benefits most often identified in the context of dual-use research apply to human health. But it is common knowledge that human health outcomes are rarely produced as a result of a single experiment, or even a line of research. This is in part because translation from basic science - and dual-use, in the main, has been a problem for basic science-to clinical or public health practice is rarely straightforward.

With this in mind, it isn't clear what stock we should place in claims about the purported benefits of dual-use research. Of our paradigm cases, the mousepox and botulinum cases present the strongest and most direct benefits. In the case of mousepox, the central translational issue that remained was to apply what was learned in a mouse model to rabbits. The benefit of a recombinant myxoma virus to human health is indirect in the sense that the eradication of an invasive pest benefits humans in second or higher-order degrees, but the achievement of those benefits was largely contingent on the application of knowledge from one virus to a related virus. This work was confirmed in 2004. ${ }^{75}$

In the case of botulinum toxin, the benefits were arguably more straightforward. Wein and Liu presented, in the context of their initial paper, recommendations for securing the milk supply against a potential terror attack. ${ }^{76}$ While Wein claimed the US Federal and State Governments ultimately never acted on those recommendations, ${ }^{77}$ the benefits were there for the taking.

Other studies, however, are not so straightforward. GOF is both most salient to a discussion of infectious disease, and has received substantial attention in the context of the deliberative process. Some proponents have suggested that, for example, GOF

\footnotetext{
${ }^{74}$ Lipsitch et al. (2016).

${ }^{75}$ Kerr et al. (2004).

${ }^{76}$ Wein and Liu (n 11).

${ }^{77}$ Wein (n 14).
} 
research involving the creation of novel pandemic influenza strains benefits human health by informing the selection of seasonal influenza strains for vaccine development. ${ }^{78}$ However, it has been argued elsewhere that this claim conflates "gainof-function," a relatively common virology technique in which novel mutations are introduced into any virus to determine which mutation leads to a change in phenotype, and GOF research involving the creation of novel variants of HPAI that have enhanced virulence, transmissibility, or host range. That is, folks who argue about the benefits of GOF research of concern tend to rely on their membership of a much larger set of experiments. ${ }^{79}$ To date, evidence that the 2011 GOF studies contributed to the particular health goal of selecting seasonal influenza strains is slight, and that which does exist is controversial. ${ }^{80}$

In the development of pandemic vaccines, moreover, the situation looks even grimmer. GOF research may provide a benefit, for example, by identifying a potential pandemic strain against which we could start to develop a vaccine. But the chances that such a vaccine will target a naturally occurring pandemic strain have been argued to be relatively slight. ${ }^{81}$ This is because what occurs in the wild is not necessarily the same as what occurs in the lab - the studies identify a path to potential pandemic status for flu, but it is not clear that this is the path, rather than one of many potential paths. $^{82}$

This is not to say that GOF research, among others, does not have value for human health. Its value, however, might be more attenuated than is typically argued. GOF studies, like so much microbiological infectious disease research, are model organism studies. They use well-characterised strains of flu (e.g. the Erasmus GOF study used a strain isolated in Indonesia in 2004) as a model for the class of pathogens known as highly pathogenic avian influenza H5N1 viruses; they also use ferrets as a model for humans in terms of the way that the flu binds to receptors in their upper respiratory tracts. ${ }^{83}$ These models could be causal models, in the sense that they purport to give accurate information about what really happens in humans (and HPAI viruses). But it is more likely, on the face of things, that they are hypothesis-generating tools that scientists use to ask questions about, for example, the nature of viral pathogenesis. ${ }^{84}$ This is useful scientific research in the sense that it can ask and answer important questions, but it is not directly or self-evidently connected to human values.

This is not unique to the beneficial applications of dual-use research. The weaponisation of a pathogen is an exercise in translation, where a promising candidate for a biological weapon is developed into munitions of some kind (e.g. biological cluster

\footnotetext{
${ }^{78}$ Schultz-Cherry et al. (2014).

${ }^{79}$ Lipsitch (2016).

${ }^{80}$ Gryphon Scientific (2016).

${ }^{81}$ Enserink (n 21); Enserink (2012).

${ }^{82}$ Lipsitch and Galvani (2014).

${ }^{83}$ Herfst and others (n 30).

${ }^{84}$ LaFollette and Shanks (1995).
} 
bombs). ${ }^{85}$ It is, moreover, a complex activity that often requires serious infrastructure, up to and including a state driven weapons programme. ${ }^{86}$ We can, and should, ask whether the risks posed by dual-use research are subject to the same translational problems as the benefits problematised above.

Where, I believe, benefits and harms differ is twofold. The first is that in many paradigm cases, the harms that are described are not vulnerable to the same translational issues as benefits. In GOF research of concern in particular, the potential harms associated with this research inhere to the recombinant viruses themselves. While weaponizing a flu virus is and would be very difficult, the harms about which we are concerned do not depend on weaponisation. The benefits of dual-use research, on the other hand, frequently require further translation.

The other reason is heuristic rather than conceptual or empirical. In documents on dual-use, there is frequently a distinction made between harms and benefits in which the benefits of dual-use research are regarded as likely and inevitable, while the risks or harms are (at least partially) discounted based on translational issues. The Fink report's discussion of the synthesis of poliovirus noted that the method was exceptionally laborious and technical, thus undermining its utility for bioterrorism; the report, however, at numerous points asserts the "great potential benefits" inhering to the life sciences without a more nuanced account of what these might be or how they might arise. ${ }^{87}$ In 2010, the US President's Commission for the Study of Bioethical Issues released a report on synthetic biology ${ }^{88}$; in an interview with The Scientist, Amy Gutmann, the chair of that committee, set apart the "likely" benefits from the "prospective" risks of the field. ${ }^{89}$ These two examples speak to a perceived tendency of advocates of a particular technology to omit the complex transitional issues facing prospective benefits, while framing risks in a way that is sceptical of their possibility. If we are going to be wary of one form of translation, we should be wary of both, and begin with an account of the difficulty of deriving benefits from emerging science and technology.

\section{Political Commitments}

Translation dovetails with political commitments. Let's assume that GOF research really did give knowledge we could use to create a vaccine against a HPAI H5N1 pandemic. And let's say that we had some reasonable expectation that this pandemic was going to be the next pandemic. Does this mean GOF research has potential benefits?

\footnotetext{
${ }^{85}$ Enemark (2005).

${ }^{86}$ Leitenberg et al. (2012), Jefferson et al. (2014), Ouagrham-Gormley (2012).

${ }^{87}$ National Research Council (2004b).

${ }^{88}$ Presidential Commission for the Study of Bioethical Issues (2010a).

${ }^{89}$ Akst (2010).
} 
Not necessarily. Vaccines don't save lives; vaccinations save lives. ${ }^{90}$ In particular, we need to move from basic science, to a candidate vaccine, to the distribution of that vaccine to patients. Even if we set aside all technical scientific obstacles to this outcome, there still comes a question of political will, and whether our institutions are designed to accomplish this kind of outcome. ${ }^{91}$

We ought to care about political and individual commitments to action, and we ought to do so symmetrically. By symmetrically, I mean that when thinking about dual-use, we ought to treat like commitments alike whether or not those commitments are toward the beneficial or malevolent uses of life sciences research and technology. This is something that has, until recently, ${ }^{92}$ been overlooked in the debate on dualuse. In examining dual-use in synthetic biology, the President's Commission for the Study of Bioethical Issues frequently claimed that the benefits of synthetic biology were imminent and sought-after, while the harms were merely prospective and not intended. ${ }^{93}$ Yet we know, for example, that global healthcare continues to labour with poor or poorly allocated resourcing, while non-state groups have explicitly advocated for the use of unconventional weapons. Given that commitments toward achieving health outcomes are frequently lacklustre or subject to weakness of will (political or otherwise), and that terrorists frequently mean what they say, it appears that we should take both at least as seriously as each other.

There are two possible approaches to how these kinds of commitments should feature into our decisions to act. ${ }^{94}$ One, a possibilist explanation, would say that our appeal to potential benefits stands if it is possible that we can produce the will to act on our commitments. Here, we only need for it to be possible to act upon our stated commitments, even if we have reason to believe we won't actually muster the will to accomplish what we set out to do so. ${ }^{95}$

Another way we could think about this is an actualist account of our motivations to act. Here, the likelihood that we will actually commit to a certain action matters as much as the likelihood that such an action would succeed if taken. On this account, we must have some belief that an actor (or set of actors) will commit to act in certain way to classify it as a potential benefit or harm, and the strength of our belief in this potential benefit or harm would vary as a function of our belief in our actor's commitment to act. (This applies for a stochastic as well as a game theoretic account of actors).

It isn't immediately clear which of these is preferable or rational to accept. On the one hand, actualism appears to conform to an intuition that we ought to really believe that someone is going to $\mathrm{X}$ before forming a belief about X's relative goodness or badness. Our belief about "a nonstate group using recombinant smallpox to eradicate

\footnotetext{
${ }^{90} \mathrm{I}$ 'm grateful to Jason Schwartz for this aphorism.

${ }^{91}$ Evans (n 64).

${ }^{92}$ Evans and Selgelid (n 69).

${ }^{93}$ Presidential Commission for the Study of Bioethical Issues (2010b).

${ }^{94}$ Jackson and Pargetter (1986).

${ }^{95}$ While Jackson and Pargetter use a binary model, Holly Lawford Smith has offered a probabilistic model of accessibility of actions by individuals and collectives. See Lawford-Smith (2012).
} 
the human race" should surely be action guiding if and only if we have reason to believe that someone genuinely intends to do so, and (in addition to technical considerations) has the will to carry out their plan. A risk that no one intends to take isn't a risk in some important sense.

On the other hand, actualism might give us a really bleak look on the potential benefits of science. Political commitments, especially-never mind the commitments of scientists who may change their research focuses or lose funding; or the public, whose concerns and focus might change_-are highly responsive to acute incentives and unresponsive to long-term needs. The West African Ebola epidemic, which received attention in 2015 and 2016 as an extreme threat, ${ }^{96}$ is now a distant memory for developed nations. Actualism might attenuate our priors about the chances of a catastrophic bioterror attack, given what such an attack would require of an actor, ${ }^{97}$ but it might also attenuate our priors about the chances of any proposed benefits of dual-use research obtaining in practice.

\section{Weighing Benefits and Risks, and Setting Priorities}

The ethical issues that arise in the context of dual-use research in the basic life sciences, including the study of infectious disease, invoke considerations of important fundamental values. Utility, characterised as the aggregate well-being of a population (up to "global" utility, i.e. the welfare of all living humans or moral status-holders) is implicated in dual-use research because of the potential for harm or benefit qua health for populations. Liberty is implicated because the governance of dual-use research — such as the potential suppression or censorship of research-may infringe upon fundamental rights to inquiry and/or speech, and professional rights to scientific freedom. And equality is implicated because those who benefit from dual-use research may be distinct from those who are harmed; the distribution of well-being (and/or liberties) is potentially morally significant in addition to its aggregate.

None of these three values is absolute, or always prior to the others. ${ }^{98}$ Scientific freedom presumably isn't assured just in cases where we expect science to benefit us, especially (as a classical utilitarian might require) a requirement to maximally benefit the globe. If this were the case, the landscape of scientific research might be completely different: for example, migraines have the same burden on health (in disability adjusted life years) as HIV/AIDS in the USA but receive 1/100th of the funding. ${ }^{99}$ In the global context, depression and injuries (among others) are underfunded relative to their overall burden of disease. ${ }^{100}$ Yet I suspect most would say that while it might be permissible to change funding priorities, mandating scientists

\footnotetext{
${ }^{96}$ Evans (2016).

${ }^{97}$ Carus (2015), Leitenberg, Zilinskas and Kuhn (n 12).

${ }^{98}$ Selgelid (2009).

${ }^{99}$ Kaiser (2015).

${ }^{100}$ Gillum et al. (2011).
} 
conduct research only certain issues would be an unjustifiable burden on their freedom (in addition to any utilitarian assertions about the role of scientific freedom in promoting health outcomes).

On the other hand, some research, as the NSABB acknowledged, might simply be too dangerous to conduct or publish. Say scientists attempted to make a highly transmissible disease-say measles-engineered to become $100 \%$ lethal. Or consider when Vincent Racaniello, a virologist at Columbia University, posited that a study to confer respiratory transmission via respiratory droplets (colloquially, to "make airborne") on HIV would present an "interesting" study. ${ }^{101}$ Arguably, both hypothetical studies pose so much risk that no appeal to liberty or equality would outweigh the value of preventing the potential harms of such research.

Finally, sometimes the conduct of risky research ought to be responsive to considerations of equality. ${ }^{102}$ Biosafety regulations in the US and elsewhere, for very dangerous pathogens, aim to protect not just those in the lab but those outside the lab. Even in cases where the harms of dual-use research are fairly limited, it is pro tanto unethical to expose individuals to risk who do not stand to benefit from our risk-taking behaviour. Biosafety regulations on dual-use research should aim not (merely) to protect against absolute utility loss, but to protect those who do not stand to benefit (or benefit as much) from scientific research against its potential risks. ${ }^{103}$

All things considered, we should adopt a position of pluralism about the ethics of dual-use research. We should aim, where possible, to guide scientific research away from dual-use research through a commitment to funding research whose benefits clearly outweigh its risks, commensurate with scientific freedom. That is, we should "design in" our ethical considerations into the scientific process from the earliest stage. ${ }^{104}$ This should be matched with institutional support to realise the benefits of dual-use research while mitigating its risks. This institutional support, moreover, should seek to distribute both risks and benefits fairly among a population, such that the risk-taking entailed by dual-use research represents a fair scheme of risk sharing within society. ${ }^{105}$ In particularly acute cases of dual-use, where the potential risks out the purported benefits of particular research, government should be empowered to impose moratoria on research or communication of dual-use. ${ }^{106}$

\footnotetext{
${ }^{101}$ See the June 1, 2014 episode of This Week in Virology. http://www.microbe.tv/twiv/twiv-287-apotentially-pandemic-podcast/. Accessed 25 March 2018.

${ }^{102}$ Considerations of justice might also enter into our equation; I set this aside here.

${ }^{103}$ Evans, Lipsitch and Levinson (n 50).

${ }^{104}$ Evans and Selgelid (n 69).

${ }^{105}$ Hansson (2011).

${ }^{106}$ Evans (n 24).
} 


\section{Conclusion}

Dual-use research is a key issue in the ethics of basic scientific research, and a particularly acute concern for research into infectious diseases that have, or can be engineered to have high virulence and transmissibility in humans. Over 17 years, the debate about dual-use has progressed from one in which scientific self-governance was held to be sufficient for the management of dual-use concerns, to the acknowledgement that at times even ostensibly beneficial scientific research may entail risks to great to justify its pursuit or publication. Future work will no doubt focus on how the life sciences research enterprise can be best designed to identify dual-use potential early, and prevent the proliferation of risky research.

\section{References}

Akst J (2010, November 19) Q\&A: ethics chair on synthetic biology. The Scientist. https:/www.the-scientist.com/?articles.view/articleNo/29368/title/Q-A--Ethics-chair-onsynthetic-biology/. Accessed 27 Apr 2018

Bartrip PWJ (2008) Myxomatosis, vol 288. IBTauris

Bostrom N (2014) Superintelligence, vol 272. OUP, Oxford

Brown KV (2017, October 18) This guy just injected himself with a DIY HIV treatment on facebook live. Gizmodo. https://gizmodo.com/this-guy-just-injected-himself-with-a-diy-hivtreatment-1819659724. Accessed 24 Mar 2018

Carus WS (2015) The history of biological weapons use: what we know and what we don't. Health Sec 13:219

Casadevall A, Imperiale MJ (2014) Risks and benefits of gain-of-function experiments with pathogens of pandemic potential, such as influenza virus: a call for a science-based discussion. mBio 5:e01730

Casadevall A, Shenk T (2012) The H5N1 moratorium controversy and debate. mBio 3:e00379

Casadevall A, Howard D, Imperiale MJ (2014) An epistemological perspective on the value of gain-of-function experiments involving pathogens with pandemic potential. mBio 5:e01875

Cello J, Paul AV, Wimmer E (2002) Chemical synthesis of poliovirus cDNA: generation of infectious virus in the absence of natural template. Science 297:1016

Centers for Disease Control and Prevention (2014a) Report on the potential exposure to anthrax

Centers for Disease Control and Prevention (2014b) Report on the inadvertent cross- contamination and shipment of a laboratory specimen with influenza virus $\mathrm{H} 5 \mathrm{~N} 1$

Central Intelligence Agency (2003) The darker bioweapons future. OTI SF 2003-108

Coleman K, Zilinskas RA (2010) Fake Botox, Real Threat. Sci Am 302:84

Connell N (2012) Immunological modulation. In Tucker JB (ed) Innovation, dual use, and security. MIT Press

Dennis B, Sun LH, FDA found more than smallpox vials in storage room. Washington Post, 16 July 2014. https://www.washingtonpost.com/national/health-science/fda-found-more-thansmallpox-vials-in-storage-room/2014/07/16/850d4b12-0d22-11e4-8341-b8072b1e7348_story. html. Accessed 12 Dec 2017

Department of Health and Human Services (2017) Framework for guiding funding decisions about proposed research involving enhanced potential pandemic pathogens (19 December 2017). https:// www.phe.gov/s3/dualuse/Documents/P3CO.pdf. Accessed 19 Dec 2017

Enemark C (2004) United States biodefense, international law, and the problem of intent. Politics Life Sci $24: 32$ 
Enserink M (2011, November) Scientists brace for media storm around controversial flu studies. Science 23. http://www.sciencemag.org/news/2011/11/scientists-brace-media-stormaround-controversial-flu-studies. Accessed $28 \mathrm{Feb} 2016$

Enserink M (2012) Public at last, H5N1 study offers insight into virus's possible path to pandemic. Science 336:1494

Evans NG (2000) Contrasting dual-use issues in biology and nuclear science. In: Selgelid MJ, Rappert B (eds) (2013) On the dual uses of science and ethics

Evans NG (2013) Great expectation-ethics, avian flu and the value of progress. J Med Ethics 39:209

Evans NG (2015) Dual-use decision making: relational and positional issues. Monash Bioeth Rev $32: 268$

Evans NG (2016) Ebola: from public health crisis to national security threat. In: Lentzos F (ed) Biological threats in the 21st century. Imperial College Press, London

Evans NG (2018) Ethical and philosophical considerations for gain-of-function policy: the importance of alternate experiments. Front Bioeng Biotechnol 6:e1875

Evans NG, Selgelid MJ (2014) Biosecurity and open-source biology: the promise and peril of distributed synthetic biological technologies. Sci Eng Ethics 21:1065

Evans NG, Lipsitch M, Levinson M (2015) The ethics of biosafety considerations in gain-of-function research resulting in the creation of potential pandemic pathogens. J Med Ethics 41:901

Fouchier RAM et al. (2012) Pause on avian flu transmission research. Science 335:400

Fouchier RAM, Garcia-Sastre A, Kawaoka Y (2012) The pause on avian H5N1 influenza virus transmission research should be ended. mBio 3:e00358

Fouchier RAM et al (2013) Transmission studies resume for avian flu. Science 339:520

GBD 2016 Causes of Death Collaborators (2017) Global, regional, and national age-sex specific mortality for 264 causes of death, 1980-2016: a systematic analysis for the Global Burden of disease study 2016. The Lancet 390:1151

Gillum LA et al (2011) NIH disease funding levels and burden of disease. PLoS ONE 6:e16837

Gryphon Scientific (2016) Risk and benefit analysis of gain of function research. Grphyon Scientific

Hansson SO Ethical criteria of risk acceptance. Erkenntnis 59:291

Henderson DA (2011) Frank Fenner (1914-2010). Nature 469:35

Herfst $S$ et al (2012) Airborne transmission of influenza a/H5N1 virus between ferrets. Science 336:1534

Herfst S, Osterhaus ADME, Fouchier RAM (2012) The future of research and publication on altered H5N1 viruses. J Inf Dis 205:1628

Hindin D, Strosnider K, Trooboff PD (2017, Jan 20) The role of export controls in regulating dual use research of concern: striking a balance between freedom of fundamental research and national security. http://sites.nationalacademies.org/cs/groups/pgasite/documents/webpage/pga_ 176436.pdf. Accessed 5 June 2017

Imai $\mathrm{M}$ et al (2012) Experimental adaptation of an influenza H5 HA confers respiratory droplet transmission to a reassortant $\mathrm{H} 5 \mathrm{HA} / \mathrm{H} 1 \mathrm{~N} 1$ virus in ferrets. Nature $486: 420$

Inglesby TV et al (2002) Anthrax as a biological weapon, 2002: updated recommendations for management. JAMA 287:2236

Jackson F, Pargetter R (1986) Oughts, options, and actualism. Philos Rev 95:233

Jackson RJ et al (1998) Infertility in mice induced by a recombinant ectromelia virus expressing mouse zona pellucida glycoprotein 31. Biol Reprod 58:152

Jackson RJ et al (2007) Expression of mouse interleukin-4 by a recombinant ectromelia virus suppresses cytolytic lymphocyte responses and overcomes genetic resistance to mousepox. J Virol 75:1205

Jefferson C, Lentzos F, Marris C (2014) Synthetic biology and biosecurity: challenging the "Myths". Front Public Health 2:449

Kaiser J (2015) What does a disease deserve? Science 350:900

Kennedy D (2005) Better never than late. Science 310:195 
Kerr PJ et al (2004) Expression of rabbit IL-4 by recombinant myxoma viruses enhances virulence and overcomes genetic resistance to myxomatosis. Virology 324:117

Kimble JB et al (2014) Alternative reassortment events leading to transmissible H9N1 influenza viruses in the ferret model. J Virol 88:66

Kleinig J, Evans NG (2013) Human flourishing, human dignity, and human rights. Law Philos 32:539

Kobasa D et al (2007) Aberrant innate immune response in lethal infection of macaques with the 1918 influenza virus. Nature 445:319

LaFollette H, Shanks N (1995) Two models of models in biomedical research. Philos Q (1950-) 45:141

Lawford-Smith H (2012) Non-ideal accessibility. Ethical Theory Moral Pract 16:653

Leitenberg M, Zilinskas RA, Kuhn JH (2012) The Soviet biological weapons program. Harvard University Press, Cambridge

Lipsitch M (2016) Comment on "Gain-of-function research and the relevance to clinical practice". J Inf Dis 214:1284

Lipsitch M, Galvani AP (2014) Ethical alternatives to experiments with novel potential pandemic pathogens. PLOS Med 11:e1001646

Lipsitch M, Evans NG, Cotton Barratt O (2016) Underprotection of unpredictable statistical lives compared to predictable ones. Risk Anal

Miller S, Selgelid MJ (2008) Ethical and philosophical consideration of the dual-use dilemma in the biological sciences, vol 76. Springer, Berlin

National Academies of Sciences, Engineering and Medicine (2016) Gain-of-Function Research: Summary of the Second Symposium. In: Millett P et al (eds) National Academies Press, Washington

National Research Council (2004) Biotechnology research in an age of terrorism. National Academies Press, Washington

National Research Council Institute of Medicine (2015) Potential risks and benefits of gain-offunction research, vol 130. National Academies Press, Washington

National Science Advisory Board for Biosecurity (2007) Proposed framework for the oversight of dual use life sciences research. National Institutes of Health, Bethesda

National Science Advisory Board for Biosecurity (2011, November 21) National science advisory board for biosecurity recommendations. National Institutes of Health, Bethesda

National Science Advisory Board for Biosecurity (2012, March 29-30) National science advisory board for biosecurity findings and recommendations

National Science Advisory Board for Biosecurity (2016) Recommendations for the evaluation and oversight of proposed gain-of-function research. Office of Science Policy

Office of Science and Technology Policy (2017, January 9) Recommended policy guidance for Departmental Development of Review Mechanisms for Potential Pandemic Pathogen Care and Oversight (P3CO). obamawhitehouse.archives.gov. https://obamawhitehouse.archives.gov/sites/ default/files/microsites/ostp/p3co-finalguidancestatement.pdf. Accessed 27 Feb 2017

Ouagrham-Gormley SB (2012) Barriers to bioweapons: intangible obstacles to proliferation. Int Sec 36:80

Palese P, Tumpey TM, Garcia-Sastre A (2006) What can we learn from reconstructing the extinct 1918 pandemic influenza virus? Immunity $24: 121$

Pennings G (2008) Ethical issues of infertility treatment in developing countries. 2008 ESHRE Monographs, p 15

Presidential Commission for the Study of Bioethical Issues (2010, December) New directions: the ethics of synthetic biology and emerging technologies. https://bioethicsarchive.georgetown. edu/pcsbi/sites/default/files/PCSBI-Synthetic-Biology-Report-12.16.10_0.pdf. Accessed 25 Mar 2018 
Presidential Commission for the Study of Bioethical Issues (2010, December) New directoins: the ethics of synthetic biology and emerging technologies. https://bioethicsarchive.georgetown. edu/pcsbi/sites/default/files/PCSBI-Synthetic-Biology-Report-12.16.10_0.pdf. Accessed 25 Mar 2018

Richard M et al (2013) Limited airborne transmission of H7N9 influenza a virus between ferrets. Nature 501:560

Robbins S et al (2005) The efficacy of cidofovir treatment of mice infected with ectromelia (mousepox) virus encoding interleukin-4. Antiviral Res 66:1

Schultz-Cherry S et al (2014) Influenza gain-of-function experiments: their role in vaccine virus recommendation and pandemic preparedness. $\mathrm{mBio} 5$ :e02430

Selgelid MJ (2009) A moderate pluralist approach to public health policy and ethics. Public Health Ethics 2:195

Selgelid MJ (2016) Gain-of-function research: ethical analysis. Sci Eng Ethics 22:923

Selgelid MJ, Weir L (2010) Reflections on the synthetic production of poliovirus. Bull At Sci 66:1

Shelton $\mathrm{H}$ et al (2013) Mutations in Haemagglutinin that affect receptor binding and pH stability increase replication of a PR8 influenza virus with $\mathrm{H} 5 \mathrm{HA}$ in the upper respiratory tract of ferrets and may contribute to transmissibility. J Gen Virol 94:1220 (PubMed-NCBI)

Sutton TC et al (2014) Airborne transmission of highly pathogenic H7N1 influenza in ferrets. J Virol 88. https://doi.org/10.1128/JVI.02765-13

Taubenberger JK, Morens DM (2006) 1918 influenza: the mother of all pandemics. Emerg Infect Dis $12: 15$

The United States Government (2013, February 21) A framework for guiding U.S. Department of Health and Human Services funding decisions about research proposals with the potential for generating highly pathogenic avian influenza H5N1 viruses that are transmissible among mammals by respiratory droplets. www.phe.gov. https://www.phe.gov/s3/dualuse/documents/ funding-hpai-h5n1.pdf. Accessed 12 Dec 2017

Tucker JB (2011) Could terrorists exploit synthetic biology? New Atlantis

Tumpey TM (2005) Characterisation of the reconstructed 1918 Spanish Influenza Pandemic Virus. Science 310:77

Watanabe $\mathrm{T}$ et al (2014) Circulating avian influenza viruses closely related to the 1918 virus have pandemic potential. Cell Host Microbe 15:692

Wein LM (2009) Homeland security: from mathematical models to policy implementation: the 2008 Philip McCord morse lecture. Oper Res 57:801

Wein LM, Liu Y (2005) Analyzing a bioterror attack on the food supply: the case of botulinum toxin in milk. Proc Natl Acad Sci 102:9984

Weir L (2012) A genealogy of global health security. Int Polit Sociol 6:322

Westwick PJ (2000) Secret science: a classified community in the national laboratories. Minerva $38: 363$

Zhang Y et al (2013) H5N1 hybrid viruses bearing 2009/H1N1 virus genes transmit in Guinea Pigs by respiratory droplet. Science 340:1459 (PubMed-NCBI)

Zhang S (2018, February 20) A biohacker regrets publicly injecting himself with CRISPR. The Atlantic. https://www-theatlantic-com.libproxy.uml.edu/science/archive/2018/02/ biohacking-stunts-crispr/553511/. Accessed 24 Mar 2018 